\title{
Analysis of Publication Status of Abstracts Presented at the Annual Meeting of the Korean Academy of Rehabilitation Medicine
}

\author{
Jae Kuk Lim, MD ${ }^{1}$, Jun Young Han, $\mathrm{MD}^{1}$, Hyun Cheol Lee, $\mathrm{MD}^{1}$, Jiwon Lee, $\mathrm{MD}^{1}$, \\ Hong Chung, $\mathrm{MD}^{2}$, Jong Moon Kim, $\mathrm{MD}^{1}$, Shin Kyoung Kim, $\mathrm{MD}^{1}$
}

Departments of ${ }^{1}$ Rehabilitation Medicine and ${ }^{2}$ Urology, Konkuk University School of Medicine, Chungju, Korea

\begin{abstract}
Objective To analyze publication rate, time to publication and the characteristics of the abstracts presented at the annual Korean Academy of Rehabilitation Medicine (KARM) meetings.

Methods A total of 1,027 abstracts presented at the 2008 and 2009 annual KARM meetings were enrolled in the database and searched for their subsequent citation in PubMed, KoreaMed, and Google Scholar.

Results The data analysis revealed that 317 (30.87\%) abstracts, were published as full-length journal articles and publication rates by subject were not significantly different. The mean time to publication was $17.17 \pm 10.48$ months, and the journals written in English $(20.39 \pm 10.20)$ required a longer duration than those written in Korean $(11.94 \pm 8.44)$ with statistical significance $(\mathrm{p}<0.001)$. There was no statistical difference $(\mathrm{p}=0.284)$ in the duration between domestic $(17.61 \pm 10.37)$ and foreign $(16.48 \pm 10.51)$ of the 220 domestic journal articles, $190(86.76 \%)$ were published in the Annals of Rehabilitation Medicine and the 97 articles published in foreign journals were scattered over 60 different journals.

Conclusion The publication rate of abstracts presented at the 2008 and 2009 annual KARM meetings was $30.87 \%$ and the mean time to publication was $17.17 \pm 10.48$ months.
\end{abstract}

Keywords Abstracts, Publications, Rehabilitation, Journal article

Received July 13, 2012; Accepted January 8, 2013

Corresponding author: Shin Kyoung Kim

Department Rehabilitation Medicine, Konkuk University Chungju Hospital, Konkuk University School of Medicine, 82 Gugwon-daero, Chungju 380-951, Korea

Tel: +82-43-840-8890, Fax: +82-43-851-3402, E-mail: kimnerve@hanmail. net

(c) This is an open-access article distributed under the terms of the Creative Commons Attribution Non-Commercial License (http://creativecommons. org/licenses/by-nc/3.0) which permits unrestricted noncommercial use, distribution, and reproduction in any medium, provided the original work is properly cited.

Copyright $\odot 2013$ by Korean Academy of Rehabilitation Medicine

\section{INTRODUCTION}

The annual Korean Academy of Rehabilitation Medicine (KARM) meeting, held every spring and fall, is a major forum for rehabilitation physicians and related health care professionals in Korea. KARM is aimed to improve the knowledge of medical science through the exchange of the latest medical experiences and scientific information. Numerous abstracts presented at the meeting contain condensed current research findings and clinical experiences and play an important role as a medium for sharing information prior to the publication of full articles. After being presented at the annual meet- 
ing, some of them are published as journal articles in the Annals of Rehabilitation Medicine (Ann Rehabil Med) as well as in medical journals throughout the world. The process of getting the abstracts published as journal articles is an exhaustive work due to the collection and analysis of clinical information, meticulously preparing manuscripts, statistical analysis of data, and subsequent critical peer review process.

In particular, the peer review is an essential process for researchers to recognize the theoretical basis of the study and apply it to clinical practice and for reviewers to exchange information in medical science. Due to this intensive work, not all the abstracts are published as fulllength articles for reasons such as insufficient data, statistical limitation, insignificant outcome of study, among others. According to a recent Cochrane Library review of 46 studies, the publication rates ranged from $11 \%$ to $78 \%$ depending on medical specialty, with an average of $45 \%$ [1]. In many fields, the publication rate of abstracts are regarded as an indicator of the quality of the scientific research presented at the meeting $[2,3]$. Furthermore, the publication rate can also be used to assess the level of such scientific meetings [4]. To the best of our knowledge, there has been no evaluations of the publication rate in the field of physical medicine and rehabilitation in Korean journals. The present study attempted to analyze the publication rate of abstracts presented at previous annual KARM meetings, the time to subsequent publication, and the abstract characteristics.

\section{MATERIALS AND METHODS}

\section{Methods}

A total of 1,027 abstracts presented between 2008 and 2009 at the annual KARM meetings were enrolled in the database. Abstracts were categorized into the following 16 subjects as listed in the program book, amputation, rehabilitation in brain disorder, cancer rehabilitation, cardiopulmonary rehabilitation, electrodiagnosis, geriatric rehabilitation, medical policy, rehabilitation in musculoskeletal and soft tissue disorders, rehabilitation in neuromuscular disorders, orthosis and prosthesis, pediatric rehabilitation, physical therapy, rehabilitation in spinal cord injury disorder, sports rehabilitation, swallowing and miscellaneous. The data base also included the title, authors, and affiliations.
Two physicians from physical medicine and rehabilitation independently investigated whether subsequent articles were published by searching the PubMed (http:// www.ncbi.nlm.nih.gov/PubMed/) database, KoreaMed database (http://www.koreamed.org/), and Google Scholar (http://scholar.google.com/) between the periods of January 2008 and June 2012. Both physicians searched for the articles by using broad keywords of abstract titles, authors' names and institutes from March 2012 to June 2012. Therefore, the follow-up periods ranged from 32 months (for the 2009 fall annual KARM meeting) to 49 months (for the 2008 spring annual KARM meeting).

When any discrepancy in search results between the two researchers occurred, the final confirmation was made after sufficient discussion. If one or more authors were identical and there was consistency in the study design and result between the abstract and the article, we assumed that as being published as well as when overall study design similar to that of the abstract, the abstract was considered as published even if there was a slight discrepancy in study scale or result. The title of the finally published article, the name of the journal, and the month and year of publication were recorded. The country and language of the published article were also recorded. The term "domestic journals" referred to journals published in Korea, and the term "foreign journals" referred to journals published in all the other countries. All foreign journals were written in English and domestic journals were written in Korean or English according to the manuscript guidelines. The term time to publication refers the duration required for the subsequent publication of the abstract as a journal article was the length of the time elapsed from the month of presentation at the annual meeting to the earlier month of publication of electronic or paper journal.

The quality of the published journals was evaluated based on Science Citation Index (SCI) and Science Citation Index Extended (SCIE) as well as the impact factors (IF) of the journals [5]. SCI published in February 2012 was used for the search and the journal IF was retrieved from Journal Citation Report (JCR) on the Thomson Scientific ISI Web of Knowledge server (http://admin-apps. webofknowledge.com/JCR/). Based on the 2011 JCR, five-year IF was recorded to exclude abrupt change of IF. The term publication rate referred to the percentage of 
the abstracts subsequently published as journal articles.

\section{Statistical analysis}

The ratio of publication by subject was analyzed using logistic regression. To evaluate correlation between the duration and the published country or language, Gehan's generalized Wilcoxon analysis was used. For statistical data analysis, SPSS ver. 12.0 (SPSS Inc., Chicago, IL, USA) was used. A p-value $<0.05$ was considered statistically significant.

Table 1. Publication rates and publication durations of each annual Korean Academy of Rehabilitation Medicine (KARM) meeting

\begin{tabular}{clcc}
\hline \multicolumn{2}{c}{$\begin{array}{c}\text { Annual KARM } \\
\text { meetings }\end{array}$} & $\begin{array}{c}\text { Publication rate } \\
\text { (\%) }\end{array}$ & $\begin{array}{c}\text { Publication } \\
\text { duration (mo) }\end{array}$ \\
\hline 2008 & Spring & 35.71 & $15.53 \pm 12.17$ \\
& Fall & 32.37 & $19.77 \pm 11.29$ \\
2009 & Spring & 28.00 & $16.62 \pm 10.32$ \\
& Fall & 29.44 & $15.28 \pm 8.80$ \\
Total & & 30.87 & $17.31 \pm 10.48$ \\
\hline
\end{tabular}

\section{RESULTS}

We analyzed 1,027 abstracts presented at the 2008 and 2009 annual KARM meetings, in which 317 abstracts (30.87\%) were published as full journal articles (Table 1). Cancer rehabilitation $(13 / 22,59.09 \%)$, cardiopulmonary rehabilitation $(13 / 28,46.43 \%)$, medical policy $(6 / 13,46.15 \%)$, and geriatric rehabilitation $(7 / 17,41.18 \%)$ showed high publication rates and sports rehabilitation $(0 / 11,0 \%)$ scored the lowest publication rate. Publication rates by subject group showed a range from $0 \%$ to $59.09 \%$ with no significant differences (Table 2).

The mean time to publication was $17.17 \pm 10.48$ months for the 317 published journal articles, in which 239 articles $(75.39 \%)$ were published within two years from presentation at the annual KARM meetings, and the longest time to publication found to be was 46 months. In addition, 220 articles $(69.40 \%)$ were published in domestic journals and 190 (86.76\%) of them were published in the Ann Rehabil Med (Fig. 1). A total of 97 articles (30.60\%) were published in foreign journals and scattered over 60 different journals. The mean time to publication in domestic journals $(17.61 \pm 10.37$ months) was modestly

Table 2. Publication rates by subject

\begin{tabular}{|c|c|c|c|c|}
\hline Subject & $\begin{array}{c}\text { No. of } \\
\text { abstracts }\end{array}$ & $\begin{array}{l}\text { No. of published } \\
\text { abstracts (\%) }\end{array}$ & $\begin{array}{c}\text { Odds ratio } \\
\text { (confidence interval) }\end{array}$ & p-value \\
\hline Amputation & 3 & $1(33.33)$ & $0.75(0.04-14.97)$ & 0.851 \\
\hline Rehabilitation in brain disorder & 236 & $81(34.32)$ & $0.78(0.13-4.79)$ & 0.782 \\
\hline Cancer rehabilitation & 22 & $13(59.09)$ & $2.17(0.30-15.70)$ & 0.444 \\
\hline Cardiopulmonary rehabilitation & 28 & $13(46.43)$ & $1.30(0.19-9.02)$ & 0.791 \\
\hline Electrodiagnosis & 133 & $31(23.31)$ & $0.46(0.07-2.85)$ & 0.401 \\
\hline Geriatric rehabilitation & 17 & $7(41.18)$ & $1.05(0.14-8.02)$ & 0.962 \\
\hline Medical policy & 13 & $6(46.15)$ & $1.29(0.16-10.45)$ & 0.814 \\
\hline $\begin{array}{l}\text { Rehabilitation in musculoskeletal \& soft } \\
\text { tissue disorder }\end{array}$ & 241 & $72(29.88)$ & $0.64(0.10-3.91)$ & 0.628 \\
\hline Rehabilitation in neuromuscular disorder & 9 & $2(22.22)$ & $0.43(0.04-4.64)$ & 0.486 \\
\hline Orthosis \& Prosthesis & 25 & $7(28.00)$ & $0.58(0.08-4.27)$ & 0.596 \\
\hline Pediatric rehabilitation & 105 & $35(33.33)$ & $0.75(0.12-4.70)$ & 0.759 \\
\hline Physical therapy & 26 & $4(15.38)$ & $0.27(0.03-2.19)$ & 0.221 \\
\hline Rehabilitation in spinal cord injury disorder & 98 & $28(28.57)$ & $0.60(0.09-3.79)$ & 0.587 \\
\hline Sports rehabilitation & 11 & $0(0)$ & $0.00(0.00)$ & 0.999 \\
\hline Swallowing & 55 & $15(27.27)$ & $0.56(0.08-3.70)$ & 0.550 \\
\hline Others & 5 & $2(40.00)$ & - & - \\
\hline Total & 1,027 & $317(30.87)$ & & \\
\hline
\end{tabular}

Analyzing method was logistic regression. 


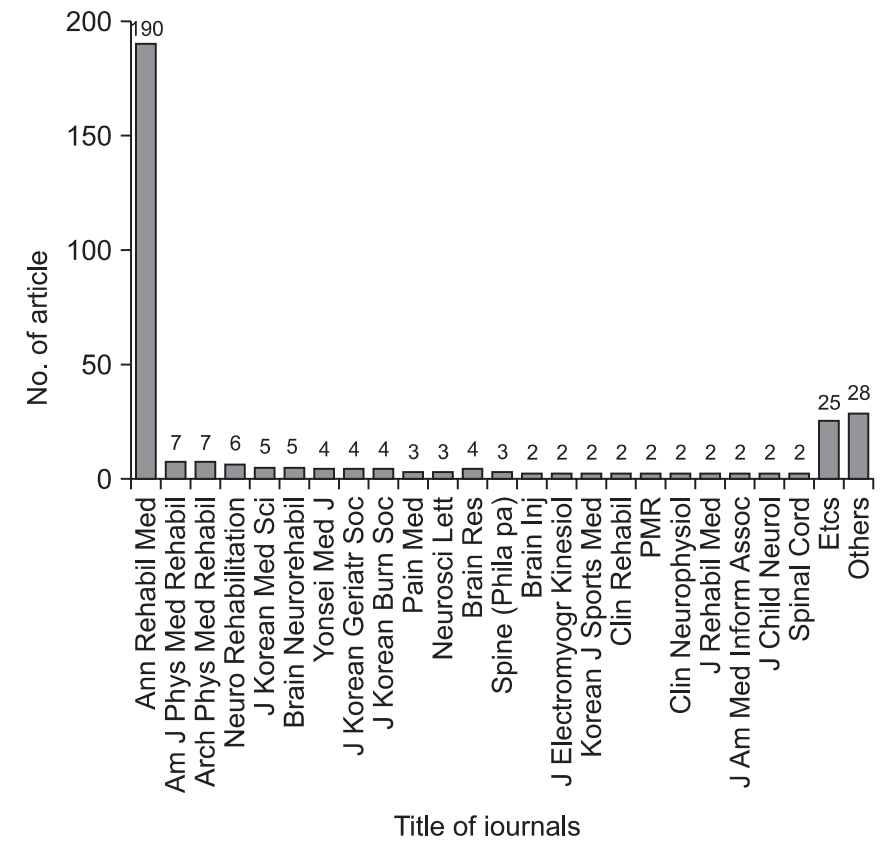

Fig. 1. The titles of journals and the number of articles registered therein are shown. Most articles published in domestic journals were concentrated in the Annals of Rehabilitation Medicine (Ann Rehabil Med), whereas articles published in foreign journals were scattered over various journals.

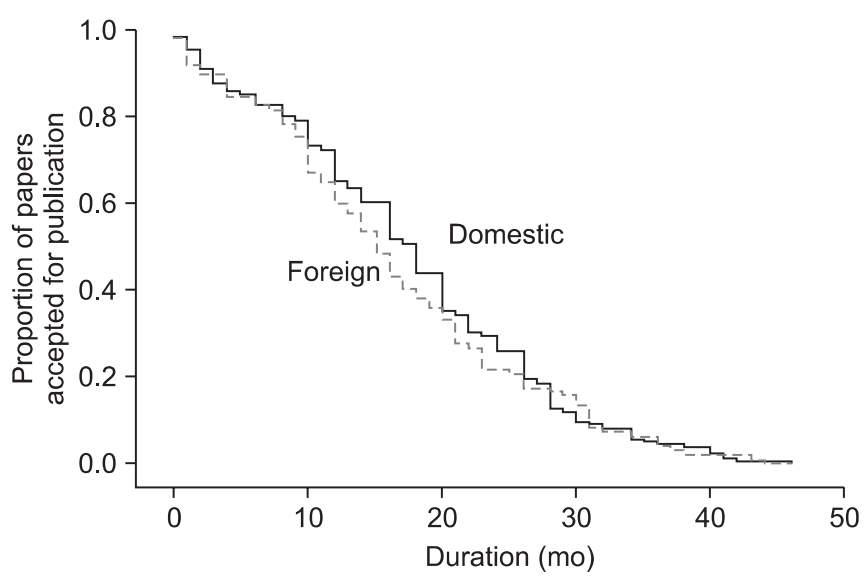

Fig. 2. On the survival graph, no significant difference between domestic and foreign journals was shown $(\mathrm{p}=0.284)$. Analyzing methods was Gehan's generalized Wilcoxon test.

longer than that of foreign journals (16.48 \pm 10.51 months) with no significant difference ( $\mathrm{p}=0.28$ ) (Fig. 2). However, the time to publication of articles written in English $(20.39 \pm 10.20$ months $)$ was significantly $(\mathrm{p}<0.001)$ longer than the articles written in Korean (11.94 \pm 8.44 months) with statistical (Fig. 3).

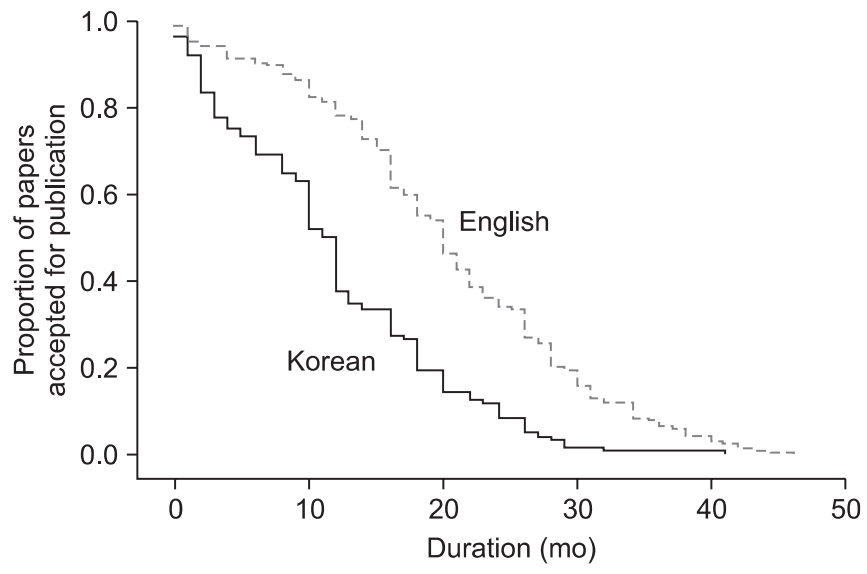

Fig. 3. The publication duration of the journals written in English was longer than that of the journals written in Korean on the survival graph $(\mathrm{p}<0.001)$. Analysis methods were Gehan's generalized Wilcoxon test.

In the 73 journals, 39 (53.42\%) foreign journals and one (1.37\%) domestic journal were listed in SCI, and 13 (15.79\%) foreign journals and one (1.37\%) domestic journal were listed in SCIE index. The five-year IF of the foreign journals ranged from 0.517 to $10.722(2.92 \pm 1.20)$ and was far higher than that of domestic journals $(1.13 \pm 0.10)$ (Table 3).

\section{DISCUSSION}

A total of $30.87 \%$ of abstracts presented at the 2008 and 2009 annual meetings were searched in PubMed or KoreaMed and Google Scholar as full-length articles. Publication rate of other scientific meetings ranged from $23.6 \%$ to $58 \%$, mean value $39.15 \%$ [2,6-10]. Although direct comparison was not available since only few other similar studies to compare in the physical medicine and rehabilitation exist in the literature, the publication rate and the publication duration in the present study showed a favorable result compared to findings from similar studies of other medical departments [2,6-10].

Ideally, all the abstracts presented should be followed by publication in journals, however, as discussed above, researchers confront many obstacles frustrating the publication of abstracts in journals. Thus, there is possibility of failure in publication, which may be caused by a variety of reasons such as lack of peer review, insufficient data, statistical limitation, and insignificant outcome of study. In practice, abstracts are presented prior to the completion of the study and usually lack the necessary 
Table 3. Journal lists and their characteristics

\begin{tabular}{|c|c|c|c|c|c|c|c|c|c|}
\hline Title & No. & $\begin{array}{l}\text { SCI/ } \\
\text { SCIE }\end{array}$ & $\begin{array}{c}5-\mathbf{y r} \\
\text { IF }\end{array}$ & Lang & Title & No. & $\begin{array}{l}\text { SCI/ } \\
\text { SCIE }\end{array}$ & 5 -yr IF & Lang \\
\hline Acta Neurobiol Exp (Wars) & 1 & & & Eng & J Korean Med Sci (K) & 5 & SCI & 1.057 & Eng \\
\hline Am J Med Genet A & 1 & SCI & 2.549 & Eng & J Korean Soc Occup Ther (K) & 1 & & & Kor \\
\hline Am J Phys Med Rehabil & 7 & SCI & 1.848 & Eng & J Med Food & 1 & SCI & 1.687 & Eng \\
\hline Ann Nucl Med & 1 & SCIE & 1.360 & Eng & J Nanosci Nanotechnol & 1 & SCI & 1.574 & Eng \\
\hline Ann Rehabil Med $(\mathrm{K})^{\mathrm{a})}$ & 190 & & & Kor/Eng & J Neurol Sci & 3 & SCI & 2.441 & Eng \\
\hline Arch Gynecol Obstet & 1 & SCIE & 1.257 & Eng & J Rehabil Med & 2 & SCIE & 2.376 & Eng \\
\hline Arch Phys Med Rehabil & 7 & SCI & 2.655 & Eng & J Spinal Cord Med & 1 & & & Eng \\
\hline J Am Art Therapy Assoc & 1 & & & Eng & J Surg Oncol & 1 & SCI & 2.365 & Eng \\
\hline BMC Neurosci & 1 & SCIE & 3.232 & Eng & Korean J Obstet Gynecol (K) & 1 & & & Kor \\
\hline Brain Inj & 2 & SCIE & 1.906 & Eng & Korean J Spine (K) & 1 & & & Eng \\
\hline Brain Lang & 1 & SCI & 3.342 & Eng & Korean J Sports Med (K) & 2 & & & Kor \\
\hline Brain Neurorehabil (K) & 5 & & & Kor/Eng & Lymphology & 1 & SCI & 1.807 & Eng \\
\hline Brain Res & 4 & SCI & 2.739 & Eng & Muscle Nerve & 1 & SCI & 2.467 & Eng \\
\hline Brain Res Bull & 1 & SCI & 2.605 & Eng & Neuroimage & 1 & SCI & 6.608 & Eng \\
\hline Brain Stimul & 1 & SCIE & 6.000 & Eng & Neurol Sci & 1 & SCI & 1.273 & Eng \\
\hline Burns & 1 & & & Eng & Neuropediatrics & 1 & SCI & 1.228 & Eng \\
\hline Cell Transplant & 1 & SCI & & Eng & Neuropsychol Rehabil & 1 & SCIE & 2.438 & Eng \\
\hline Chin Med J (Engl) & 1 & SCI & 0.991 & Eng & Neurorehabil Neural Repair & 1 & SCIE & 4.757 & Eng \\
\hline Clin Neurophysiol & 2 & SCI & 3.760 & Eng & NeuroRehabilitation & 6 & & & Eng \\
\hline Clin Rehabil & 2 & SCI & 2.530 & Eng & Neuroreport & 1 & SCI & 1.989 & Eng \\
\hline $\begin{array}{l}\text { Comput Methods } \\
\text { Programs Biomed }\end{array}$ & 1 & SCI & 1.531 & Eng & Neurosci Lett & 3 & SCI & 2.168 & Eng \\
\hline Dev Med Child Neurol & 2 & SCI & 3.400 & Eng & Neuroscience & 1 & SCI & 3.458 & Eng \\
\hline Eur J Appl Physiol & 1 & SCI & 2.321 & Eng & Oral Oncol & 1 & SCI & 3.056 & Eng \\
\hline Eur Neurol & 2 & SCI & 1.793 & Eng & Pain Med & 3 & SCIE & 2.546 & Eng \\
\hline Exp Brain Res & 1 & SCI & 2.533 & Eng & Pain Physician & 1 & SCIE & 10.722 & Eng \\
\hline Gynecol Oncol & 1 & SCI & 3.592 & Eng & Pediatr Int & 1 & & & Eng \\
\hline Indian J Phys Med Rehabil & 1 & & & Eng & PM R & 2 & & & Eng \\
\hline Int J Neurosci & 1 & & & Eng & $\begin{array}{l}\text { Rehabil Eng Assist Technol Soc } \\
\text { Korea (K) }\end{array}$ & 1 & & & Eng \\
\hline J Am Med Inform Assoc & 2 & SCI & 4.329 & Eng & Scand J Rheumatol & 1 & SCI & 2.520 & Eng \\
\hline $\begin{array}{l}\text { J Back Musculoskelet Re- } \\
\text { habil }\end{array}$ & 1 & SCIE & 0.517 & Eng & Spinal Cord & 2 & SCIE & 2.113 & Eng \\
\hline J Child Neurol & 2 & SCI & 1.821 & Eng & Spine (Phila Pa 1976) & 3 & SCI & 2.949 & Eng \\
\hline J Electromyogr Kinesiol & 2 & SCI & 2.269 & Eng & Spine J & 1 & & & Eng \\
\hline J Ethnopharmacol & 1 & SCI & 3.728 & Eng & Stroke & 1 & SCI & 6.468 & Eng \\
\hline J Korean Burn Soc (K) & 4 & & & Kor & Support Care Cancer & 1 & SCI & 2.746 & Eng \\
\hline J Korean Epilepsy Soc (K) & 1 & & & Kor & Trans KIEE (K) & 1 & & & Kor \\
\hline J Korean Geriatr Soc $(\mathrm{K})$ & 4 & & & Kor & Yonsei Med J (K) & 4 & SCIE & 1.206 & Eng \\
\hline
\end{tabular}

Journals are abbreviated according to the conventional ISO abbreviations.

SCI, Science Citation Index; SCIE, Science Citation Index Extended; IF, impact factors; Lang, language.

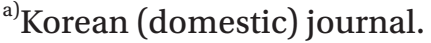


details for reviewers to criticize, thus abstracts with inadequate data were also be presented at the conferences. Based on the analysis from the present study, some abstracts were with overlapping subjects and some others were similar to previously conducted studies in domestic or foreign journals. Thus, not all these abstracts presented in the meetings were ultimately published in journals, the possible reasons are individual academic interests or involvement of non-academic factors such as external requests [11]. Researchers might conduct studies requested by public institutions, corporations, other medical departments, or non-medical scientists among others. In some cases, abstracts were transformed into further new studies or merged with the existing studies which might influence the publication rate.

Differences in the time to publication between domestic and foreign journals were not significant. The fact that a longer duration was required for publication in domestic journals was surprise for us, although it was not statistically significant. This could be due the development of the online submission system, e-mail and faster post submission services than in the past [12], which means that physical distance is no longer an obstacle in submitting journal articles. Moreover, the Ann Rehabil Med, the most targeted domestic journal, does not have an electronic submission and article processing options. Occasionally, articles accepted, but not able to be published in paper journals due to the lack of space, were released via electronic journals prior to being published in their paper journals. When comparing the time to publication in domestic journals in Korean and English, the latter was longer than the former indicating the language barrier as a critical obstacle in the publication of a journal article. Since 2011 Ann Rehabil Med also recommends the submissions in English, in an effort to be an international journal.

The present analyses indicated that, most articles were published in domestic journals and majority of them in the Ann Rehabil Med, however, the articles published in foreign journals were scattered over various journals this could be due to the fact that physical medicine and rehabilitation are the subjects of diverse nature. Nevertheless, since there were not many high impact domestic journals, apparently most articles were targeted to the Ann Rehabil Med.

Other reports suggest that, the longest publication du- ration was about 40 months $[13,14]$, and our data also similar to the above mentioned studies. Considering the above, follow-up periods of the present study (32 to 49 months) might be too short for abstracts presented at the 2009 annual KARM meetings to be published as journal articles.

Since PubMed and KoreaMed were used as searching tools, we only could search the Medline database and the Korean Association of Medical Journal Edition database, Google Scholar was used to find articles that were not registered in the above database. However, there might be more journals not registered in the above databases and the possibility that we could have missed some published article cannot be excluded. As a result, the actual publication rate might be higher than that of the present study.

Most journals recommend having keywords on the line after the end of the abstracts, using appropriate Medical Subject Headings as listed by the National Library of Medicine. The absence of keywords in the abstracts of the 2008 and 2009 annual meetings of KARM rendered the search process difficult and might influence the accuracy of the search process.

The other limitations of the present study are the fact that except directly asking the authors of the abstracts, there is no way to identify whether the presented abstracts were submitted and how long it took for the submitted articles to be finally accepted. According to questionnaires for residents, $57 \%$ of projects had been abandoned or remained incomplete due to their lack of time, lack of interest, and faculty's lack of interest [15].

In conclusion, the publication rate of abstracts presented from 2008 to 2009 annual KARM meetings was $30.87 \%$ and the mean duration for subsequent publication was $17.17 \pm 10.48$ months.

\section{CONFLICT OF INTEREST}

No potential conflict of interest relevant to this article was reported.

\section{REFERENCES}

1. Scherer RW, Langenberg P, von Elm E. Full publication of results initially presented in abstracts. Cochrane Database Syst Rev 2007;(2):MR000005. 
2. Scherer RW, Dickersin K, Langenberg P. Full publication of results initially presented in abstracts: a metaanalysis. JAMA 1994;272:158-62.

3. Gorman RL, Oderda GM. Publication of presented abstracts at annual scientific meetings: a measure of quality? Vet Hum Toxicol 1990;32:470-2.

4. Castillo J, Garcia-Guasch R, Cifuentes I. Fate of abstracts from the Paris 1995 European Society of Anaesthesiologists meeting. Eur J Anaesthesiol 2002;19:88893.

5. Saha S, Saint S, Christakis DA. Impact factor: a valid measure of journal quality? J Med Libr Assoc 2003;91:42-6.

6. Chung JH, Autorino R, Kang DH, Lee JY, Moon HS, Choi HY, et al. Fate of abstracts presented at the annual meeting of the Korean urological association. Korean J Urol 2012;53:280-4.

7. Yun EH, Chun KA, Kim YJ, Park SH. Fate of Abstracts presented at the scientific meetings of the Korean radiological society. J Korean Radiol Soc 1999;41:102934.

8. Chung KJ, Lee JH, Kim YH, Kim TG, Ha JH. How many presentations are published as full papers? Arch Plast Surg 2012;39:238-43.

9. Kim JO, Choi BW, Kim JH, Song KJ, Lee KB. Observational analysis of Korean society of spine surgery an- nual congress: (2001-05) free paper: from presentation to publication. J Korean Soc Spine Surg 2011;18:19-23.

10. Ha TH, Yoon DY, Goo DH, Chang SK, Seo YL, Yun EJ, et al. Publication rates for abstracts presented by Korean investigators at major radiology meetings. Korean J Radiol 2008;9:303-11.

11. Dickersin K, Min YI, Meinert CL. Factors influencing publication of research results. Follow-up of applications submitted to two institutional review boards. JAMA 1992;267:374-8.

12. Govender P, Buckley O, McAuley G, O’Brien J, Torreggiani WC. Does online submission of manuscripts improve efficiency? JBR-BTR 2008;91:231-4.

13. Autorino R, Quarto G, Sio MD, Lima E, Quarto E, Damiano R, et al. Fate of abstracts presented at the World Congress of Endourology: are they followed by publication in peer-reviewed journals? J Endourol 2006;20:996-1001.

14. Smith WA, Cancel QV, Tseng TY, Sultan S, Vieweg J, Dahm P. Factors associated with the full publication of studies presented in abstract form at the annual meeting of the American Urological Association. J Urol 2007;177:1084-8.

15. Gill S, Levin A, Djurdjev O, Yoshida EM. Obstacles to residents' conducting research and predictors of publication. Acad Med 2001;76:477. 